\title{
NOTE
}

\section{QUALITATIVE DIFFERENCE BETWEEN BLEOMYCIN AND RADIATION EFFEGTS ON CELL VIABILITY}

\author{
Hideya Endo
}

Cancer Research Institute, Faculty of Medicine, Kyushu University, Fukuoka, Japan

(Received July 30, 1970)

Results of previous work on the mode of action of the antitumor antibiotic bleomycin (BLM), discovered by UMEZAWA et al. ${ }^{1}$, indicate that this antibiotic breaks DNA strands of microbial as well as mammalian cells in vivo and in vitro $o^{2,8,4,5,7)}$.

In connection with the breakage of DNA strands due to X-ray and ultraviolet (UV) irradiation, it seemed very important to clarify whether the action of BLM is qualitatively similar to those of X-ray and UV irradiation. A suitable approach to this problem would be the study of the lethal effect of BLM on some radiation sensitive mutants of $E$. coli carrying excision-repair defects for UV or X-ray damage. This communication describes the results of such an analysis, which show that the action of BLM is different from those of UV and X-ray irradiation.

Three isogenic sub-strains of E. coli K12, AB1157, AB 1885 (UV sensitive, HowardFLANDERS) $^{6}$ ) and AB2463 (UV and $\mathrm{X}$-ray sensitive, HowardFLANDERS $^{8)}$ and four strains of the E. coli B series, B (Benzer), B (Berkeley), B (HARM) and $B_{S-1}$ (UV and $X-$ ray sensitive, $\left.\mathrm{H}_{\text {ILL }}\right)^{9)}$ were employed for these experiments. The $E$. coli $\mathrm{K}$ strains
Fig. 1. Effect of bleomycin- $A_{2}$ on the viability of three isogenic substrains of $E$. coli $\mathrm{K} 12$; AB1157, AB1885 (UV sensitive) and $A B 2463$ (UV and $\mathrm{X}$-ray sensitive)

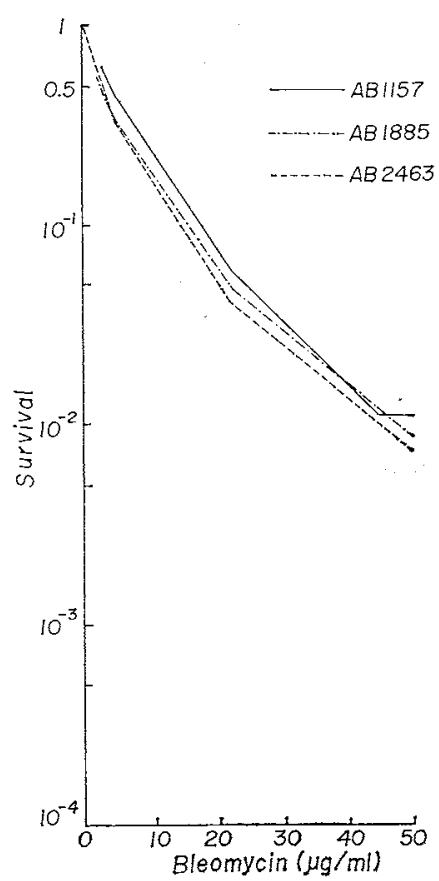

Fig. 2. Effect of bleomycin- $\mathrm{A}_{2}$ on the viability of the strains of $E$. coli B series; B (BENZER), B (BERKELEX), B (HARM), and $B_{S-1}$ (UV, $X$-ray sensitive, HILL)

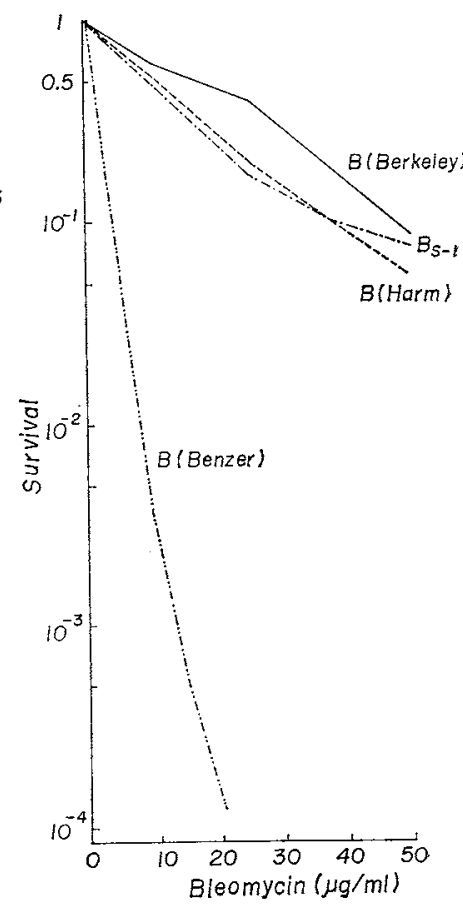


Table 1. The sensitivity of the $E$. coli strains to UV and X-ray irradiation

\begin{tabular}{l|c|c|c|c|c|c|c|c|c}
\hline \multirow{2}{*}{ Strain } & \multicolumn{5}{|c|}{ UV irradiation (sec) } & \multicolumn{3}{|c}{ X-ray irradiation (K rad) } \\
\cline { 2 - 10 } & 0 & 5 & 15 & 25 & 30 & 60 & 0 & 5 & 15 \\
\hline $\mathrm{AB} 1157$ & 1 & & & & 0.7 & 0.5 & 1 & & $4.5 \times 10^{-2}$ \\
$\mathrm{AB} 1885$ & 1 & $1.2 \times 10^{-1}$ & $2.2 \times 10^{-3}$ & & & & & & \\
$\mathrm{AB} 2463$ & 1 & $2.8 \times 10^{-1}$ & $5.2 \times 10^{-2}$ & & & & 1 & $2.5 \times 10^{-2}$ & $<5.5 \times 10^{-5}$ \\
\hline $\mathrm{B}(\mathrm{BENZER})$ & 1 & & 0.9 & & & 0.7 & 1 & $2.3 \times 10^{-1}$ & $7.1 \times 10^{-3}$ \\
$\mathrm{~B}_{\mathrm{S}-1}$ & 1 & $1.6 \times 10^{-3}$ & & $<1.6 \times 10^{-6}$ & & & 1 & $1.6 \times 10^{-2}$ & $<1.6 \times 10^{-5}$ \\
\hline
\end{tabular}

Each strain, grown logarithmically in EM medium was harvested, washed once with EM buffer and was resuspended in the same buffer to obtain a final cell concentration of about $2 \sim 6 \times 10^{8} / \mathrm{ml}$. Aliquots of each cell suspension were exposed to UV irradiation of the 15 watt Hitachi germicidal lamp at a distance of $80 \mathrm{~cm}$. Other aliquots of the respective cell suspension were exposed to $\mathrm{X}$-ray irradiation under the following condition : $180 \mathrm{kVp} X$-rays, no filtration, HVL $0.36 \mathrm{mmCu}$, dose rate $570 \mathrm{rads} / \mathrm{min}$, at room temperature.

The numbers of surviving cells in each irradiated fraction were expressed as relative values, referred to unirradiated aliquots taken as 1 .

fold with the buffer to stop further reaction of the drug and were finally plated on nutrient agar after appropriate further dilutions. The colonies of surviving cells were counted after an overnight incubation of the plates.

As shown in Fig. 1, the survial curves of the three isogenic strains, AB1157, AB 1885 (UV sensitive), and AB2463 (UV and $\mathrm{X}$-ray sensitive), treated with $\mathrm{BLM}-\mathrm{A}_{2}$ were quite similar. Since the UV- and X-ray sensitivity of AB1885 and AB 2463 were confirmed to be well retained as shown in Table 1 , the possibility was eliminated that the above results might be due to the use of revertants. Thus, it is concluded that the mode of lethal action of BLM-A $\mathrm{A}_{2}$ evidently differs from that of UV and X-ray irradiation.

Similar experiments were also carried out using strains of the E. coli B series. As shown in Fig. 2, the survival curves of $B$ (BERKELEY) and $B\left(\mathrm{H}_{\mathrm{ARM}}\right)$ are in accord with that of $B_{\mathrm{s}-1}$ ( $\mathrm{H}_{\text {ILL }}$ ), a strain which was also confirmed in the present study to be sensitive to $U V$ and $X$-ray irradiation (Table 1 ). This experiment, especially the comparison of strains B (BERKELEY) and $B_{S-1}$ (HILL), again indicates that there is no relationship between the mode of lethal action of BLM- $\mathrm{A}_{2}$ and that of UV- and X-ray irradiation. It is further noted that $E$. coli $\mathrm{B}$ (BENZER) used in this experiment was particularly sensitive to $\mathrm{BLM}-\mathrm{A}_{2}$ as compared with other $\mathrm{B}$ strains so far tested. In order to look for one possible cause of difference between the BLM sensitivity of $E$. coli B (BENZER) and the other $B$ strains, the respective cell suspensions or cell-free extracts were incubated with BLM. The residual activity of this antibiotic in each mixture was biologically determined, but no difference could be observed. It is therefore unlikely that the difference in BLM sensitivity between $E$. coli $B$ (BENZER) and the cther B strains may be caused by different contents of BLM inactivating enzyme. Details of this experiment, together with other related data will be published elsewhere.

Regarding the lethal effect of BLM on cultured mammalian cells, TERAsima et al. ${ }^{10}$ ) recently reported that the change in sensitivity of cells during various stages of the division cycle is quite similar to that for $\mathrm{X}$-ray irradiation. Histopathological observations of lung fibrosis induced in patients by administration of large doses of BLM also showed some similarity with those induced by X-ray treatment. ${ }^{11}$ These findings, together with some clinical observations that certain $\mathrm{X}$-ray sensitive tumors well responded to BLM, ${ }^{12)}$ seem to offer a basis of an argument that the real mode of action of BLM may be similar to that of $\mathrm{X}$-rays. However, our present data do not cope with these ideas, and rather seem to support the view that BLM is different from socalled radiomimetic agents including $\mathrm{X}$-rays, the more so since this antibiotic has virtually no effect on bone-marrow ${ }^{13)}$.

This work was supported partly by a Grantin-Aid for Scientific Research from the Ministry 
of Education. The author wishes to express hearty thanks to Dr. HAMAO UMEZAWA, Director of the Institute of Microbial Chemistry for the supply of bleomycin- $A_{2}$, his continuous interest and valuable discussion. The author's thanks are also due to Dr. Nozomu Otsusi, Dr. Minoru IshizAWA, Kyushu University for their valuable discussion, and to Dr. Köj MAsuda, Kyushu University for his collaboration on $\mathrm{X}$-ray irradiation.

According to the personal communication of Dr. Kenshi Suzukr, National Institute of Radiological Sciences, Chiba, they also obtained the similar results with the present study, which indicate that the action of bleomycin is different from that of radiation.

\section{References}

1) UmezaWa, H.; K. MAeda, T. TAKeUChI \& Y. OKamr: New antibiotics, bleomycin $A$ and B. J. Antibiotics, Ser. A $19: 200 \sim 209,1966$

2) Suzuki, H. ; K. NagaI, H. Yamaki, N. TANAKA \& H. UMEZAWA: On the mechanism of action of bleomycin: Scission of DNA strands in vitro and in vivo. J. Antibiotics $22: 446 \sim$ 448, 1969

3) Nagai, K.; H. Suzuki, N. Tanaka \& H. UMEZAWA: Decrease of melting temperature and single strand scission of DNA by bleomycin in the presence of 2-mercaptoethanol. J. Antibiotics $22: 569 \sim 573,1969$

4) NagaI, K.; H. Yamaki, H. Suzuki, N. Tanaka \& H. Umezawa: The combined effects of bleomycin and sulfhydryl compound on the thermal denaturation of DNA. Biochim. Biophys. Acta 179:165 171, 1969
5) NagaI, K.; H. Suzuri, N. Tanaka \& H. UMEZAWA: Decrease of melting temperature and single strand scission of DNA by bleo. mycin in the presence of hydrogen peroxide. J. Antibiotics 22:624 628, 1969

6) Boyce, R. P. \& P. Howard-Flanders: Genetic control of DNA breakdown and repair in $E$. coli $\mathrm{K}-12$ treated with mitomycin C or ultraviolet light. Z. Vererbungsl. 95 : $345 \sim 350,1964$

7) Terasima, T.; M. Yasukawa \& H. Umezawa: Breaks and rejoining or DNA in cultured mammalian cells treated with bleomycin. Gann (Jap. J. Cancer Res.) 61 : in press

8) Howard-Flanders, P. \& L. Theriot: Mutants of Escherichia coli K-12 defective in DNA repair and in genetic recombination. Genetics $53: 1137 \sim 1150,1966$

9) GreenberG, J.: Loci for radiation sensitivity in Escherichia coli strain $\mathrm{B}_{\mathrm{s}-1}$. Genetics $55: 193 \sim 201,1967$

10) Terasima, T. \& H. Umezawa: Lethal effect of bleomycin on cultured mammalian cells. J. Antibiotics $23: 300 \sim 304,1970$

11) Matsui, K. \& H. Morihisa: Nine autopsy cases of pulmonary fibrosis observed in bleomycin applied cases. Proc. Jap. Cancer Ass., 28 th Gen. Mtg. Kanazawa, p. 242, 1969

12) UmEZAwA, H.: Studies on bleomycin (special lecture). J. Jap. Cancer Th. $5: 2 \sim 7,1970$

13) Krmura, I.; T. Ohnoshi, I. Kunimasa \& J. Takano: Studies on the treatment of malignant tumors with bleomycin. I. Effects on bone marrow and lymp node. Proc. Jap. Cancer Ass., 28 th Gen. Mtg. Kanazawa, p. 244, 1969 